\title{
The Role of Gaming Platforms in Young Males' Trajectories of Technical Expertise
}

Joe Baxter-Webb

Transactions of the Digital Games Research Association

2016, Vol. 2, No. 3, pp. 89-115

ISSN 2328-9422

http://todigra.org

TEXT: Licensed under Creative Commons Attribution (CC BY-NC- ND

2.5) http://creativecommons.org/licenses/by-nc- nd/2.5/

IMAGES: All images appearing in this work are property of the respective copyright owners, and are not released into the Creative Commons. The respective owners reserve all rights.

\section{ABSTRACT}

Studies of gender in videogame culture have often suggested that games provide a source of informal learning about technology, and that the perceived masculinity of the medium means that this benefit goes mainly to boys. The author's research interrogates and expands upon this "technosocialization” theory of games. This paper presents a case-study based on interviews with male students $(\mathrm{n}=18)$ studying ICT (Information and Communications Technology) in the UK, and illustrates the complexity of relationships between gaming and their interest (or indifference) toward computing careers. 
90 ToDiGRA

\section{KEYWORDS}

informal learning, platform studies, biographical research, youth game making

\section{INTRODUCTION}

Much of the existing literature on gaming and gender has suggested a connection between gaming and enthusiasm toward computing careers (Wajcman, 1991; Cassell and Jenkins, 2000; de Castell \& Jenson, 2004; 2007; 2008; Kerr, 2003; Beavis \& Charles, 2007; Carter, 2006). More recently, similar cases have been made for studying the gaming habits of young men who fall outside of the typically white, middle-class "geek" stereotype, and how gaming habits might affect their interest in Computer Science (DiSalvo \& Bruckman, 2010). I refer to this body of research as holding a techno-socialization theory of games; viewing games as tools for the acquisition of skills and attitudes associated with computing careers, as well as for the construction of individuals' relationships with technology more broadly.

The idea that leisure uses of computers might shape individual career trajectories also feeds into broader conversations about "digital divide(s)" or how society may be becoming stratified based on patterns of technological ownership, access and use (Warschauer, 2004; Van Dijk, 2006). What might seem like natural talent in an educational setting may often be the result of what Goode and colleagues (2012, p. 48) term "preparatory priviledge"; the result of a domestic head start with computers. Researchers of computing education in the US contend that young people from affluent households - or at least the children of more technically literate parents - tend to receive this type of advantage (Ching et al, 2005; Seiter, 2007; Good et al, 2012).

What I hope to illustrate is that, although there is a clear connection between the male-domination of computing careers and parts of gaming culture, we need to be careful to differentiate when gaming does and 
does not provide a tangiable bridge into careers. Post-compulsory study in computer-specific fields is unpopular across genders in Germany, the UK and the US, despite being more popular among boys (Schulte and Knobelsdorf, 2007; DiSalvo and Bruckman, 2009; Department for Education, 2011; 2013). In the UK this has often been attributed to a "boring” curriculum focussing on use of office software (Fuller et al, 2009; Royal Society, 2010). Students may disengage from courses because their own informal learning surpasses what is on offer at school (Carter, 2006). General claims about "videogames" or even "male-centric gaming culture” may neglect pertinent differences between gaming platforms and the cultures which arise around them. As DiSalvo and Bruckman (2009) argue, low uptake of Computer Science courses suggests that perhaps boys are not receiveing as much of a benefit from gaming as previously thought.

Based on a series of semi-structured interviews in post-16 ICT classes at two UK schools (following four years of the author working as a teaching assistant in the subject) this paper illustrates how some boys consciously link their interest in IT careers to their histories of gaming. These connections are made in ways which are often heavily dependent on parental involvement and upon the types of gaming platforms available at home.

\section{Games as Technological Socialization: A Theory of Learning Through Leisure}

The arrival of the home videogame is a key moment in the "genderizing" of human-computer interactions (Cassell, 2002). In the US, female enrolment in Computer Science degrees began to drop in the mid 1980s as computers and consoles entered American homes, usually marketed as “toys for boys” (Henn, 2014) with no similar drop-off in female enrolment in Medicine, Law and Physical Sciences degrees. Computing was gradually "masculinised”, through boys dominating informal learning spaces and being the initial target market for games and hobbyist magazines (Haddon, 1990; Wajcman, 1991, Lumbar, 1998). 
Microcomputers of the 1980s saw young players of games begin to make their own using the BASIC language (Fifre-Shaw et al 1985; Mohamedali et al, 1987; Veraart, 2011; Saarikoski \& Suominen, 2009; Švelch, 2013; Swallwell, 2008; Swalwell, 2012). These machines remained popular for longer in Europe and the UK (Loguidice and Barton, 2014, p. 138) leading to a geographically-specific generation of "bedroom coders" who went on to work in industry. In the 1990s, personal computers became more modular, and hobbyist scenes shifted from an emphasis on making whole games, to modifying parts of existing ones (Au, 2002; Kücklich, 2005; Seif El-Nasr \& Smith, 2006; Hayes, 2008) and the assembly of high-end gaming machines (Simon, 2007). However, literacy expert Elisabeth Hayes suggests the following:

'We have little specific or systematic documentation of individual players' trajectories of learning and development of expertise - which games are more likely to trigger such learning, which players engage in such practices, or what conditions seem to be important in supporting this trajectory of expertise.” (Hayes, 2008, p. 222)

Hayes went on to survey high-school pupils, concluding (p. 224) that most games enjoyed by school-age girls do not have the same "affordances for technology-related learning” (such as modding). DiSalvo and Bruckman (2009, p. 276) conducted similar research with undergraduates, arguing that the theory of games as techno-socialization is troubled by continually falling enrolment in Computer Science. They suggest that the special connection between gaming and Computer Science has eroded as gaming became more integrated into mainstream culture. Like Hayes, they recommend a closer investigation into the specifics of any gaming-computing relationship which does exist at the present time.

\section{Players and Platforms}

Platform differentiation is important here because it is predominantly PC gaming which supports the types of hobbyism which might lead to a deeper interest in computing (Seif El-Nasr and Smith, 2006, Beavis \& Charles, 2007; Hayes, 2008). Laurie Taylor (2007, p. 223) has argued 
that the interplay between gaming platforms and the communities which arise around them is often overlooked. The "platform studies" perspective takes a social constructivist approach to technology, asserting that society and technology affect each other mutually (Bogost and Montford, 2009) but research in the techno-socialization literature has rarely foregrounded platforms themselves.

Hardware and software platforms limit or constrain the end experience in ways which attract particular groups of players. Many game genres are PC-specific (MMOs, MOBAs, RTS) partly due to differences in userinput, but also to the comparatively late entry of consoles into online gaming. Gee notes that the control schema of the PC attracts some while repelling others and that "these matters are connected to their identities as game players” (2003, p. 34). One fruitful way to describe and analyse these intersections of identity with technological use and aptitude is Dovey and Kennedy's use of “technicity” (Dovey and Kenney, 2006). The concept of technicity lets us consider not just types of players but also how these relate to technology more generally, in this case, due to their association with specific platforms and what that might mean in terms of their other values.

Generally, the difference between consoles and PCs can be described in terms of openness; both in relation to the physicality of the hardware and the design of the relevant operating system. Consoles have traditionally been closed systems, built to run proprietary software sanctioned by the console manufacturer (Kerr, 2006) and, more recently, other entertainment media. In contrast, PCs are multi-purpose open systems; players have more opportunities to alter or create game content, and the machines themselves tend to be assembled and upgraded piecemeal. Mainstream console manufacturers have tended to hide away their machines' inner workings in order to minimize technical barriers to entry, thus allowing for the largest possible target market. As a result, those involved in PC-specific gaming cultures often express pride in their own gaming activities being in some way more creative or technical (Simon, 2007). 
The PC is associated with technological innovations such as online play (Kierriemuir, 2006) but has historically been a comparatively small niche within digital games. Writing in 2006, Kerr noted that console games made up the majority of total software sales (p. 39) while the 2012 Oxford Handbook of the Digital Economy (Lee, p. 85) cites PC games as less than $5 \%$ of total gaming software revenues. PC-gaming network Steam had 65 million accounts in late 2013, compared to 110 million on PlayStation Network and 48 million on Xbox Live (Prasuethsut, 2013). Nintendo platforms sold the most software units for the 2006-2011 period, while the PC ranked lowest on sales-by-platform (Babb and Terry, 2013, p. 40). Attempts to compare the cost of similarly powered consoles and PCs often to inflate console prices by including the television cost; despite the fact that most people own televisions prior to consoles.

Socioeconomic status can determine not only access to gaming technology but also how is perceived. Itō (2009, p. 35) has suggested that young people's engagement with games is mediated by parental attitudes to technology; with middle-class parents more likely to champion personal computers as educational while negatively associating consoles with “couch potato" televisual culture. One British study of 1,287 6-17 year olds found working-class families more likely to own a games console (Livingstone, 2002). DiSalvo and Bruckman (2010) found the young African-American men in their study did not see playing an MMO as a "social" experience as long-term fans might, due to having no access to or interest in gaming PCs, while Andrews' (2008, p. 206) survey of 195 American high school students found that that those from high socioeconomic backgrounds were more likely to report a general interest in gaming, and to prefer PCs over consoles. Andrews characterises this is a type of digital divide, exaccerbated by the relative quality of Internet connections and perhaps "discomfort with keyboard-based interfaces” among lower-socioeconomic-status students (p. 209).

Method and Sample: Thematic Interviews with Teenage ICT 


\section{Students}

The interviewees contacted for this research were a mixed sample of adult IT professionals [ $\mathrm{n}=21$ ] and young people studying ICT $^{1}$ as an elective, post-compulsory subject [ $\mathrm{n}=19]$, although this paper focuses on the latter. Semi-structured interviews were used to obtain "technicity biographies" - narrative accounts of growing up with (and becoming interested in) technologies. These stories tended to revolve around turning points and transitions, narratives of "becoming" a certain type of person. The younger sample was predominantly (like the researcher) male and white British, with only one female student in one of the two classes visited (she was interviewed but did not fall into either of the two main categories discussed later). One of the boys was black British and three had originated from countries in Eastern Europe in the previous four to six years. Although no data was collected to describe the social class of respondents, both schools had catchment zones falling in the top quartile for socioeconomic deprivation according the 2010 Index of Multiple Deprivation (Open Data Communities, 2014). Contrasts with groups from more affluent areas would be useful (but cannot be made at the present time).

Opening questions related to the respondents' present work or studentship (e.g. “why did you choose to study IT?”). I would then request a personal history of interactions with computers, seeking to identify conditions of access (e.g. whether respondents had sole access to home computers) and the role of gate-keeping individuals (such as family members and/or peers). Although I did have a "checklist of questions" (Merrill and West, 2009, p. 119) I generally aimed to take a "non-directive” approach, allowing the interviewee to talk "at length in his or her own terms" (Atkinson and Hammersly, 2007, p. 101) with minimal prompts.

Biographical research offers two types of data; the events themselves, and the telling of those events. Exaggerations or omissions need not 
be problematic, when regarded as a type of data in their own right. From a sociological perspective, Jedlowski (2001) and Marotzki (2004) both emphasize biographical data as a way of understanding how subjects process their experiences. I generally found that older and more confident respondents were happier to tell their life story with fewer prompts, meaning I had to employ my "checklist of questions” more frequently for the younger students. The teenagers were less likely (or able) to offer accounts pre-dating their own adolescence, and this was perhaps compounded by the fact that, due to time pressure, some of these interviews were conducted in friendship pairs. The younger students, therefore, produced accounts which were not as typically "biographical”, but which still offered an insight into the nuances of the phenomena being described. Conducting some interviews in pairs, it turned out, became a way to observe performative behaviour/speech among peers; for example, one student might tell me that they "only" play one particular platform, and then another would correct them and say "but you have console $x$ ”. This highlighted contradictions between the play practices which they really engaged in, and how they wanted to present their player identities. The importance of identifying perfomative answers to questions of player tastes has been highlighted in several previous studies (Carr, 2005; Jenson and de Castell, 2008; DeVane and Squire, 2008).

Most of what has been discussed in the paper thus far leads toward the hypothesis that "individual players' trajectories of learning” (Hayes, 2008, p. 222) are heavily dependent on the platforms upon which they play, due to the design of the personal computer offering more opportunities for "incidental” learning; learning which occurs as a "by-product of some other activity" (Marsick and Watkins, 1990, p. 8). However, to avoid skewing answers toward this area, I applied one general "rule" throughout these interviews; I would avoid asking questions about gaming unless the respondents themselves raised the topic (which most eventually did). This is in accordance with Taylor and Bogdan's advice about being "truthful but vague" (1984, p. 25) with regards to divulging the research agenda to participants, in order to avoid skewing responses. 


\section{Orientations to ICT (and to Gaming)}

Interviews were analysed and emergent themes noted. Similar experiences or ways of speaking about careers and leisure activities related to the school subject (ICT) were grouped, and three categories appeared to emerge. These represented different orientations; different levels of "seriousness" in their perception of technology and its uses; different types of technicity. These categories are reductive and simplistic, and some young people move between them as they speak; but they provide a way of understanding the home-school dynamics at work. These were:

- The "means to an end" orientation

- The "console gaming enthusiasts"

- The "PC gamer/tinkerers"

The "means to an end" orientation described around half of the group; young people whose interest in computers was tangential to some other goal. For them, IT is a general employability skill for fields such as business or policing, or for applications such as graphic, web or product design. Their career interests involved the computer as a tool, but computers themselves were not the primary focus. No obvious pattern could be observed about the gaming habits of this group, except that it was diverse (ranging from FIFA to World of Warcraft) and tended not to be something they spoke about early on in the conversations.

In comparison, the other two groups - the "console gaming enthusiasts" and the "PC gamer/tinkerers" - foregrounded gaming when describing their interest in computers. It is these two groups who will be the focus of the remainder of this discussion, as they illustrate two different types of relationship between gaming and computing interest.

\section{The Console Gaming Enthusiasts}

This group played almost exclusively on consoles, although many owned 
laptops primarily for homework, social media, films and music etc. The term "console gaming enthusiasts" describes both their preferred play platform and their stated career goals. For the majority of the class, Xbox360 gaming was an important form of social interaction outside of school during evenings and weekends. Most members of this group cited game development as a career aspiration, but had very little experience of actually making games at any level. Their teacher had introduced them to Scratch and Java, but despite their stated career goal, only one had installed any game-making software at home. Their interest in games seemed to directly inform their choice of ICT as a subject, but this had not extended over into their home-lives, and I was uncertain as to whether "game developer" was simply a cool job to express an interest in, with elements of peer-pressure in these responses.

This apparent lack of hobbyist game-making at home stood in direct contrast to the biographies I had gathered from adult IT workers; four of whom had been developers at a local games company, and had made games outside of school in their teenage years, using a variety of tools including QBasic and Flash. After observing that many game developers had been making games at home before any such opportunity arose at school, it seemed disconcerting that so many of the younger interviewees viewed development jobs as something they could obtain purely through formal education, and with sparse experience prior to university. Take, for example, the following exchange between myself and Craig, one of the console gaming enthusiasts, following his expression of interest in a development career:

Researcher: Have you looked into game-making programs or anything like that at home?

Mmm, no. I haven't really looked into it to be fair. I've just

Craig: like, obviously started looking for universities. And I don't think I'm gonna get into university. I need two As and they're all Cs at the moment, so I haven't really looked into it much.

Even if Craig were to achieve the necessary grades to enter a university 
course in game development or computer science, how would he fare in the games job market, alongside hobbyists with the advantage of having programmed since their early teens, and who were in the habit of constant self-tutorage through trial-and-error and internet tutorials?

One student among the console game enthusiasts, Dmitri, had tried using Unreal Development Kit, but said that his laptop was not powerful enough to run the software. He had gone on to try GameMaker - a 2D game-making tool - but found its codeless drag-and-drop scripting confusing without guidance. Dmitri's story also suggested to me that, unlike those who began hobbyist programming in the 1980s and early 1990s, the graphical standards set by today's games meant he would have to seriously lower his expectations of what was achievable by a single, inexperienced creator. It was rare for any of the boys in this class to make reference to simpler indie games when they spoke about what they played. For those of us working with young people in game-making workshops or classrooms, it is worth considering how first-time creators have to reorient their tastes away from mainstream AAA production values.

Overall, a clear link could be drawn between the console gamers' decision to study IT and their gaming, although it was unclear how exactly their gaming contributed to any sort of useful subject knowledge. In many cases, gaming was one of the first things they mentioned when asked about their job aspirations, although the conducting of pair interviews may have meant that these responses were in some way performative. But while a game development pathway seems attractive to them because it orients around an object of pleasure, most had found only frustration in the actual process of trying to make games. They had yet to develop the sort of challenge-driven, self-determining mind-set I had come to associate with professional programmers and game developers throughout the other parts of my research. It seems fair to say that they had unrealistic expectations of how competitive the industry might be, and the expectations that would be placed on them to constantly update their skills through self-tutorage and experimentation (this was reported 
quite widely among my adult interviewees; not only the game developers but by software developers in general).

It would be easy to dismiss expressions of interest in game development as an unattainable dream for teenage gamers who are largely uninformed about the realities of work in the games industry. However, this perspective would be a double standard; we generally do not discourage aspiring young filmmakers or authors from studying Film or Literature on this basis, so why do the same with games? It would also be fair, however, to expect young people aspiring in any creative field to have dabbled outside of school, but that did not seem to be the case for this group of young men.

\section{The PC Gamer/Tinkerers}

One of the classrooms I visited was also home to a small group of three boys who, either through parental intervention or personal curiosity, had become computing hobbyists between the ages of ten and sixteen, building gaming PCs or programming small games at home. Their gaming preferences were closely bound up with hobbyist computing, with histories of informal learning mirroring those of the adult IT professionals mentioned earlier.

One boy, Andrei, was described by one peer as the "class expert" on computers; the person they would go to for advice on laptop or PC purchases. While the console gaming enthusiasts only spoke about relatively well-known, recent games, Andrei's experience of building machines with a parent had exposed him to much older genres of game, something he seemed proud of. The following excerpt is given unabridged, because it illustrates how Andrei's response to the question "why are you studying ICT" flows so succinctly into his gaming. The excerpt also illustrates how shared knowledge about games can be a "crucial aspect of building rapport” (DeVane and Squire, 2008, p. 270). 
My job interests are, I plan to become a network administrator, which is, administrator of a network. So I thought that picking IT would probably be a first choice. I also have a background

Andrei: $\quad$ in computers, worked with computers with my dad, built a couple of models, played with software, different types of software like Photoshop, uh, programming software like Microsoft Studio and I've used different versions of Windows which dates back to Windows 98 or 95 .

Researcher: Network administrator is very specific. How did you get interested in computer networking?

Well gaming, and also just for experimental reasons. We've Andrei: [Andrei and friend] set up PHP chat clients and networks and stuff.

Researcher:

So do you have a preference for what you play on? Like console or PC?

Andrei: $\quad$ Uh yeah PC is my preference.

Researcher: What do you play?

Andrei: $\quad$ MMOs like DC Universe, wargames like Planetside 2. Sometimes I play Warcraft 3 with other people.

Researcher: Warcraft 3 is quite old now... you seem quite knowledgeable about older games.

We still play new games, but we have played old games, like Andrei: $\quad$ I've played the Ultima series. Which dates back to almost 2 decades ago.

Andrei stands out among this group because his experience largely mirrors that of the adult IT workers who were interviewed at other stages of the research. For example, one game developer $(\mathrm{m} / 26)$ gave the following example (using the same series of games) of how his PC gaming related to his identification as a "computer person”: “when you're ten and you edit the autoexec so you can have a bit more RAM so you can play Ultima 8 - that sort of thing sticks with you”. Another $(\mathrm{m} / 24)$ recalled building his first computer, and being proud that it ran Quake 3 Arena (id Software, 1999) at the "magic number” of 125 frames per second. These examples have different foci (software vs hardware) but both illustrate how, given the right set of conditions, tasks which 
might frustrate most people can become early sources of self-efficacy with regards computers; stepping stones on the transition from being an unconfident "user" of computers toward being a "designer”; a manipulator and builder of systems (Schulte and Knobelsdorf, 2007). Schulte and Knobelsdorf similarly found that games were often highlighted as a favorite initial starting application in the biographical narratives offered by Computer Science majors (p. 34). This is perhaps why the majority of empirical studies of incidental technical learning in gaming culture have tended to focus on computers and not consoles.

Another point about the PC gamer/tinkerer teenagers was that all owned at least one or two of the more popular consoles. Although they foreground the PC as their preference, the peer norm of sociable console gaming meant they had to also have a console in order to be able to play with most of their friends at evenings and weekends. This illustrates a socioeconomic barrier to becoming this sort of PC gamer/tinkerer; a young person would either need to have enough money for both platforms or stick to the personal computer and miss out on a lot of social activities. As one student (Eli, m/19) in the "means to an end" category put it:

My friends tend to play more on the consoles... more of their friends are on it, probably online experience is better, you can talk to your friends um, or probably coz they're not used to playing games on a

Eli: computer ... I don't really think they would get computers just for games, they mainly use them for social networking and to do their work but for gaming, nah I think they would just get a game console really.

It is worth noting that not every young person who played on PCs fitted into this category. One student, as mentioned earlier, played the PC-only World of Warcraft but expressed little interest in these aspects of computing, and was primarily interested in football and performing arts. Those in the "tinkerer" category tended to have parents who were either hobbyists themselves, or who at least supported the hobby by providing their 
children with resources and encouragement. In contrast, the other students either had low-end laptops, or limited access to shared family computers.

The tinkerers differed from the console gaming enthusiasts in the type of job aspirations they spoke about. Opening questions about job aspirations were met with "network manager", "IT technician” and "computer programmer". Unlike the console gaming enthusiasts, these were gamers who did not aspire directly to game development, despite having more tools at their disposal should they have wanted to. Lewis, for example, describes his self-tutorage practices in the following way:

I chose IT because I wanna go into computer programming, 'cause I like programming things. I normally do quite a lot at home as well.

Lewis: I've been making little games, for about 2 years? Since I was like 14 ... You read webpages and look stuff up; see what people have programmed, get other games, get the programming for the actual game.

Note that "programming" is the dominant theme in this excerpt. As with many of the older IT workers I learn programming. Lewis talks about programming as inherently pleasurable; the coding aspect of game-making is, to him, part of the enjoyment, whereas those who said they wanted to be developers tended to view programming as an irritating hurdle; a chore they had briefly had to wrestle with at school. Schulte and Knobelsdorf (2007) similarly noticed a difference between students, where those unaffiliated with Computer Science were more likely to view such tasks as pleasurable challenges.

As noted earlier, this game-making computer hobbyist orientation coincides with research on 1980s hobbyist scenes, all of which found that making games was as much about improving and evidencing programming skills as it was the games themselves (although it is important to note that this trend may change as newer software for making games without programming become more popular). What appears to be the case, in most of the examples given here, is that the transition between 
being an unconfident "user" and a confident "designer" appears to have happened primarily at home, aided not by "gaming” as a general cultural field, but within an ecosystem of activities where PC gaming and hobbyist computing overlap.

\section{Hobbyist Computing as "Serious" Leisure}

The differences noted here between types of player technicity underscore an issue educationalists and sociologists may face when conceiving of "games" or "gaming” in too general a way. Characterizing gaming as a leisure activity invites us to step back and look not at specific instances of play with particular games, but with ongoing interactions with specific platforms, interrogating ways in which those platforms provide or limit opportunities for informal learning.

Scholars within leisure studies have disagreed on what constitutes leisure. Kaplan (1960, pp. 22-25) offered a relatively "common sense” understanding of leisure as an enjoyable and voluntary antithesis to work. Others have warned this "residual" definition of leisure as time "left over" is a false dichotomy which does not accurately describe most people’s experience (Roberts, 2006). Any activity may be subjectively experienced as leisure by participants (Kelly, 1981) and those whose occupations are particularly emotionally absorbing may not differentiate leisure from work (Lewis, 2003; Adib \& Guerrier 2003). Rather, these two concepts should be viewed as interrelated, as part of a "life-course framework” (Kelly and Kelly, 1994) which emphasizes how "people develop a form a reciprocity between paid work and their other roles and identities found in their leisure activities” (Best, 2010, p. 43).

Here I have adopted Stebbins' (1982) concept of “serious leisure” to better describe how the hobbyist relationship manifests in the cases of some of my interviewees, and the type of reciprocity Best identifies between careers and leisure. It could be said that much of the ideology that has arisen around PC gaming cultures comes from a sense of pride in having a stoic attitude, saving up money, carefully building a machine and 
learning what every part of it does. This, for Stebbins, is what differentiates normal leisure (entertainment, time-passing etc.) from serious leisure, in which participants associate their activities with self-betterment as opposed to pure hedonism. The term describes the subjective seriousness attached to some activities by participants. Such attachments may, however, have material knock-on effects in the form of knowledge acquisition; incidental learning which occurs as a "by-product of some other activity” (Marsick and Watkins, 1990, p. 8).

\section{SERIOUS LEISURE AND THE ACCUMULATION OF Cultural Capital}

This "head start" that some may experience (through PC gaming as serious leisure) is what Pierre Bourdieu (1986) described as the domestic transmission of "cultural capital"; a set of knowledge valued within the dominant culture. With reference to Bourdieu's work, Seiter (2007) uses an analogy between a piano and a computer to illustrate how knowledge gained informally at home is more "sticky"; becomes embodied and "second nature" to the point that young people with more access to either a piano or computer would appear "naturally" talented at the relevant subject in school. When tasked with high-school essays on Shakespeare, those who have early domestic experience may have a higher degree of comfort with the subject matter, and may even enjoy studying it more than many of their peers.

When children are given opportunities to "mess about" with technology without too much fear of reprisal (a privilege which has historically been afforded more often to boys) they develop confidence and learn to teach themselves. We already have a healthy body of work dealing with the part that videogames have played in the gendering of the IT workforce. Social class may also present barriers for young people, not only the economic cost obtaining technologies, but also attitudinal barriers, such as whether they have been socialized to reject solitary studiousness or computer-based labour. The early-years home context is one of the most powerful factors in determining young people's orientation to computers 
(Ching et al, 2005; Seiter, 2007) how they see themselves as computer users and whether they identify as a "computer person”. Barron et al. (2009) conducted interviews with eight school children and their parents, and identified the ways in which technologically literate parents support their children's learning. The data explored in the paper futher illustrates how parental relationships to some extent configure the young person's developing technicity; ultimately it is parents who decide which technologies exist in the home and conditions of access and support, all of which affects what young people might "take away" from their gaming.

\section{When Does Gaming Capital Become Cultural Capital?}

Cultural capital was originally a way to theorize how types of knowledge were valued in ways which would award individuals a sort of social maneuverability within the dominant culture. In The Forms of Capital, Bourdieu (1986, p. 248) described cultural capital as "convertible, in certain conditions, into economic capital" and something which "may be institutionalized in the form of educational qualifications". Cultural capital may be objectified or embodied, often in interrelated ways, for example the ownership of a computer (objectified cultural capital) and the knowledge of how to use it in ways valued by the dominant culture (embodied cultural capital). It is impossible to invoke cultural capital within games studies without also dealing with "gaming capital". Consalvo's original formulation of gaming capital aims to:

“...capture how being a member of game culture is about more than playing games or even playing them well. It's being knowledgeable about game releases and secrets... It's having opinions about which game magazines are better and the best sites for walkthroughs on the Internet”. (Consalvo, 2007, p. 18)

Gaming capital helps us to theorize how different groups of people engage with games in different ways, and how "gamer" may not simply mean "someone who plays games". Although Consalvo admits that some groups may be disproportionately excluded from the means (or desire) to possess gaming capital (p. 36; p. 124) the effect of social class is left 
largely undiscussed. This redirection of Bourdieu's terms toward understanding how one group operates, without reference to the rest of society, goes against Bourdieu's original notion of cultural capital which meant to illustrate:

“...how taste and style preferences have the real concrete consequence of installing and reproducing social hierarchies on the basis of differences in social agents' ability to master the codes of the legitimate culture.” (Jensen, 2006, p. 260)

Jensen wrote this in critique of Thornton's (1995) development of cultural capital into "subcultural capital" along the lines that it disregards Bourdieu's original intention of cultural capital as a means to understand differentiation between social actors based on symbols of social class a criticism which could also apply to gaming capital. As Seiter (2007, p. 35) argues, even very technical accomplishments by players may not easily convert into paying jobs without "other kinds of material support" such as money and social networks.

It is possible to remarry gaming capital with Bourdieu's class-oriented concept of cultural capital by looking at how particular types of gaming knowledge might relate to the socio-economic conditions of a person's early years, and how these might prefigure whether that person might easily "fit" into the prevailing cultures in a given field. Walsh and Apperly adapt gaming capital into the context of media literacy education, which allows them to evaluate how gaming capital may sit between and alongside Bourdieu's existing forms of capital. They advocate:

“...understanding youths' accumulation and exchange of gaming capital in order to understand how it impacts on other forms of capital, rather than viewing gaming [as] a discrete entertainment oriented part time that has no meaning outside itself.” (Walsh \& Apperly, 2009, p. 7)

This paper has aimed to take the approach advocated above by emphasizing the importance of platforms. When an interest in gaming serves as an entry-point to technical careers, it usually does so in platform-specific ways. Personal computers present challenges to accessibility which 
are mostly erased in the design of consoles, but these challenges have tended to provide tools for young people to begin feeling confident with computers; to identify themselves as "computer people”, and to become the sorts of people who tell you they want to be technicians or programmers. Open systems which allow for "tinkering”, and a domestic environment that supports such activity, are the link between gaming culture more generally, and the more technical and "serious" leisure practices in hobbyist computing. Accomplishing technical tasks related to games is a way of evidencing a type of technicity. The "PC gamer/tinkerer" is a technicity where overcoming the platform-specific hurdles associated with PC games often leads to that initial identification as a "computer person”, and where types of platform-specific gaming capital can potentially convert into cultural capital in the broader sense.

\section{BIBLIOGRAPHY}

Adib, A., \& Guerrier, Y. (2003). The interlocking of gender with nationality, race, ethnicity and class: the narratives of women in hotel work. Gender, Work \& Organization, 10(4), 413-432.

Atkinson, P. and Hammersley, M. (2007) Ethnography: Principles in Practice. 3rd Edition. New York: Taylor and Francis.

$\mathrm{Au}$, J. W. (2002). Triumph of the mod. [Online] Available at: http://www.salon.com/tech/feature/2002/04/16/modding/print.html [Accessed 2015 January 5].

Andrews, G. (2008). Gameplay, gender, and socioeconomic status in two American high schools. E-Learning, 5(2), 199-213.

Babb, J. \& Terry, N. (2013). Comparing video game sales by gaming platform. Southwestern Economic Review, 40(1), 25-46.

Barron, B. Martin, C. K. Takeuchi, L. and Fithian, R. (2009). Parents as learning partners in the development of technological fluency. International Journal of Learning and Media, 1(2), 55-57. 
Beavis, C. \& Charles, C. (2007). Would the "real" girl gamer please stand up? Gender, LANcafes and the reformulation of the "girl" gamer. Gender and Education, 19(6), 691-705.

Best, S. (2009). Leisure Studies: Themes and Perspectives. Sage.

Bogost, I. \& Montfort, N. (2009). Platform studies: frequently questioned answers. In Proceedings of the 2009 Digital Arts and Culture Conference.

Bourdieu, P. (1986). The forms of capital. In Richardson, J. (ed.) Handbook of Theory and Research for the Sociology of Education. New York: Greenwood. pp. 241-258.

Carr, D. (2005). Contexts, gaming pleasures, and gendered preferences. Simulation \& Gaming, 36(4), 464-482.

Carter, L. (2006). Why students with an apparent aptitude for computer science don't choose to major in computer science. ACM SIGCSE Bulletin, 38(1), 27-31.

Cassell, J. and Jenkins, H. (2000). Chess for girls? Feminism and computer games. In Cassell, J. and Jenkins, H, eds. From Barbie to Mortal Kombat: Gender and Computer Games. London: MIT Press. pp. 2-36.

Cassell, J. (2002). Genderizing human-computer interaction. In The Human-Computer Interaction Handbook. L. Erlbaum Associates, pp. 401-412.

Ching, C. Basham, J. and Jang, E. (2005) The legacy of the digital divide: Gender and socioeconomic status, and early exposure as predicators of full-spectrum technology use among young adults. Urban Education, 40(4), 394-411.

Consalvo, M. (2007). Cheating: Gaining Advantage in Videogames. MIT Press.

DC Universe Online. (2011). Daybreak Game Company. 
de Castell, S. \& Jenson, J. (2004). Paying attention to attention: New economies for learning. Educational Theory, 54, 381-397.

de Castell, S. \& Jenson, J. (2007). Girls and gaming: Gender research, "progress" and the death of interpretation. In Proceedings of the 2007 Digital Games Research Association Conference. Available at: http://www.digra.org/dl/db/07311.36536.pdf [Accessed 3 November 2014].

de Castell, S. \& Jenson, J. (2008). Theorizing gender and digital gameplay: Oversights, accidents and surprises. Eludamos: Journal for Computer Game Culture, 2(1), 15-25.

Department for Education, (2011). Education and Training Statistics for the United Kingdom (2008/09).

Department for Education, (2013). Education and Training Statistics for the United Kingdom (2010/11).

DeVane, B., \& Squire, K. D. (2008). The meaning of race and violence in Grand Theft Auto San Andreas. Games and Culture, 3(3-4), 264-285.

DiSalvo, B. \& Bruckman, A. (2009). Questioning video games’ influence on CS interest. In Proceedings of the 4th International Conference on the Foundations of Digital Games, pp. 272-278.

DiSalvo, B. \& Bruckman, A. (2010). Race and gender in play practices: young African American males. In Proceedings of the Fifth International Conference on the Foundations of Digital Games, pp. 56-63.

Dovey, J., \& Kennedy, H. W. (2006). Game Cultures: Computer Games As New Media. McGraw-Hill International.

Ensmenger, N. (2010). Making programming masculine. In Misa, T. J. (ed.), Gender Codes: Why Women are Leaving Computing, pp. 115-139. Wiley. 
Fife-Schaw, C., Breakwell, G. M., Lee, T. \& Spencer, J. (1985). Patterns of teenage computer usage. Journal of Computer Assisted Learning, 2(3), 152-161.

Fuller, A., Connor, H., Johnston, B. \& Turbin, J. (2009). The Evaluation of Computer Clubs for Girls: Final Report to SEEDA. Southampton Education School: University of Southampton.

Gee, J. P. (2003). What Video Games Have to Teach Us About Learning and Literacy. New York: Palgrave.

Goode, J. Chapman, G. \& Margolis, J. (2012). Beyond curriculum: The exploring computer science program. ACM Inroads, 3(2), 47-53.

Haddon, L., (1990). Researching Gender and Home Computers. [Online] Available at: http:/www.lse.ac.uk/media@lse/whoswho/academicstaff/lesliehaddon/genderpc.pdf [Accessed 23 October 2014].

Hayes, E., (2008). Girls, gaming, and trajectories of IT expertise. In Y. B. Kafai, C.

Heeter, J. Denner \& J. Y. Sun (eds.), Beyond Barbie and Mortal Kombat: New Perspectives on Gender and Gaming. London: MIT Press, pp. 217-230.

Henn, S. (2014). When women stopped coding. Npr.org. 21 October. [Accessed 18 March 2015].

Itō, M. (2009). Engineering Play: A Cultural History of Children's Software. London: MIT Press.

Jedlowski, P. (2001). Memory and sociology: Themes and issues. In Time Society, 10(1), 29-44.

Jensen, S. Q. (2006). Rethinking subcultural capital. Young, 14(3), 257-276. 
Kaplan, M. (1960). Leisure in America: A Social Inquiry. Wiley.

Kelly, J. R. (1981). Leisure interaction and the social dialectic. Social Forces, 60(2), 304-322.

Kelly, J. R., \& Kelly, J. R. (1994). Multiple dimensions of meaning in the domains of work, family, and leisure. Journal of Leisure Research, 26(3), 250-274.

Kerr, A. (2003). Girls/women just want to have fun - A study of adult female players of digital games. In Proceedings of the 2003 Digital Games Research Association Conference.

Kerr, A. (2006). The business of making digital games. In J. Rutter \& J. Bryce (eds.), Understanding Digital Games. London: Sage, pp. 36-58.

Kirriemuir, J. (2006). A history of digital games. In J. Rutter \& J. Bryce (eds.), Understanding Digital Games. London: Sage, pp. 21-35.

Kücklich, J. (2005). Precarious playbour: Modders and the digital games industry. The Fibreculture Journal, 5.

Lee, R. S. (2012). Home videogame platforms. In M. Peitz \& J. Waldfogel (eds.), The Oxford Handbook of The Digital Economy. Oxford: Oxford University Press, pp. 83-107.

Lewis, S. (2003). The integration of paid work and the rest of life. Is post-industrial work the new leisure? Leisure Studies, 22(4), 343-345.

Livingstone, S. (2002). Young People and New Media: Childhood and the Changing Media Environment. London: Sage.

Loguidice, B. \& Barton, M. (2014). Vintage Game Consoles. Oxon: Focal Press.

Lumbar, S. (1998). Men/women/production/consumption. In R. 
Horowitz \& A. Mohen (eds.), His and Hers: Gender, Consumption, and Technology. University Press of Virginia, pp. 7-38.

Margolis, J., \& Fisher, A. (2003). Unlocking the Clubhouse: Women in Computing. MIT Press.

Marsick, V. J. \& Watkins, K. E. (1990). Informal and Incidental Learning in the Workplace. Routledge.

Marotzki, W. (2004). Qualitative biographical research. In Flick, U., von Kardoff, E. \& Steinke, I. (eds.), A Companion to Qualitative Research. Sage, pp. 101-107.

Merrill, B. and West, L. (2009) Using Biographical Methods in Social Research. London: Sage.

Mohamedali, M. H., Messer, D. J. \& Fletcher, B. C. (1987). Factors affecting microcomputer use and programming ability of secondary school children. Journal of Computer Assisted Learning, 3(4), 224-239.

Open Data Communities (2014). Online Deprivation Map (based on 2010 Index of Multiple Deprivation). Available at: http://opendatacommunities.org/deprivation/map [Accessed 15 April 2014].

Planetside 2 (2012). Daybreak Game Company.

Prasuethsut, L. (2013). Steam rises to the console challenge with $65 \mathrm{~m}$ users, surpassing Xbox Live. TechRadar. [Online] Available at: http://www.techradar.com/news/gaming/steam-rises-to-the-consolechallenge-with-65m-users-surpasses-xbox-live-1195004 [Accessed 30 October 2014].

Quake III Arena (1999). id Software.

Roberts, K. (2006). Leisure in Contemporary Society. Cabi.

Royal Society (2010). Current ICT and Computer Science in schools 
- damaging to UK's future economic prospects? [Online] Available at: http://royalsociety.org/Current-ICT-and-Computer-Science-in-schools/ [Accessed 11 December 2014].

Saarikoski, P. \& Suominen, J. (2009). Computer hobbyists and the gaming industry in Finland. IEEE Annals of the History of Computing, 31(3), 20-33.

Schulte, C. \& Knobelsdorf, M. (2007). Attitudes towards computer science - computing experiences as a starting point and barrier to computer science. In Proceedings of the Third International Workshop on Computing Education Research, pp. 27-38.

Seif El-Nasr, M. \& Smith, B. (2006). Learning through game modding. Computers in Entertainment, 4(1).

Seiter, E. (2007). Practicing at home: Computers, pianos and cultural capital. In McPherson, T. (ed.), Digital Youth, Innovation, and the Unexpected. Massachusetts: MIT Press. pp. 27-52.

Simon, B. (2007). Geek chic: Machine aesthetics, digital gaming, and the cultural politics of the case mod. Games and Culture, 2(3), 175-193.

Stebbins, R.A. (1982). Serious leisure: A conceptual statement. The Pacific Sociological Review, 25(2), 251-272.

Švelch, J. (2013). Say it with a computer game: Hobby computer culture and the non-entertainment uses of homebrew games in the 1980s Czechoslovakia. Game Studies, 13(2).

Swallwell, M. (2008). 1980s Home Coding: The Art of Amateur Programming. In S. Brennan \& S. Ballard (eds.), The Aotearoa Digital Arts Reader. Auckland: Clouds/Aotearoa Digital Arts Trust, pp. 193-201.

Swalwell, M. (2012). Questions about the usefulness of microcomputers in 1980s Australia. Media International Australia, 143(1), 63-77. 
Taylor, L. N. (2007). Platform Dependent: Console and Computer Cultures. In J. P. Williams \& J.H. Smith (eds.), The Players' Realm: Studies on the Culture of Video Games and Gaming. Jefferson, NC: MacFarland \& Co., pp. 223-238.

Taylor, S. J. \& Bogdan, R. (1984). Introduction to Qualitative Research Methods: The Search for Meanings. New York: John Wiley \& Sons.

Thornton, S. (1995). Club Cultures: Music, Media and Subcultural Capital. Cambridge: Polity Press.

Ultima Series. (1981-). Origin/Blue Sky/Looking Glass/EA/Bioware Mythic

Van Dijk, J. A. (2006). Digital divide research, achievements and shortcomings. Poetics, 34(4), 221-235.

Varma, R. (2007). Women in computing: The role of geek culture. Science as Culture, 16(4), 359-376.

Veraart, F. (2011). Losing meanings: Computer games in Dutch domestic use, 1975-2000. IEEE Annals of the History of Computing, 33(2), 52-65.

Wajcman, J. (1991). Feminism Confronts Technology. Cambridge: Polity Press.

Walsh, C., \& Apperley, T. (2009). Gaming capital: Rethinking literacy. In Proceedings of the AARE 2008 International Education Research Conference.

Warcraft 3: Reign of Chaos (2002). Blizzard Entertainment.

Warschauer, M. (2004). Technology and Social Inclusion: Rethinking the Digital Divide. MIT Press.

World of Warcraft (2004-). Blizzard Entertainment. 